University of Wollongong

Research Online

Faculty of Social Sciences - Papers (Archive) Faculty of Arts, Social Sciences \& Humanities

2015

Ethnically diverse transport behaviours: an Australian perspective

Natascha Klocker

University of Wollongong, natascha@uow.edu.au

Stephanie Toole

University of Wollongong, st921@uowmail.edu.au

Alexander Tindale

University of Wollongong, at196@uowmail.edu.au

Sophie-May Kerr

University of Wollongong, smk534@uowmail.edu.au

Follow this and additional works at: https://ro.uow.edu.au/sspapers

Part of the Education Commons, and the Social and Behavioral Sciences Commons

Research Online is the open access institutional repository for the University of Wollongong. For further information contact the UOW Library: research-pubs@uow.edu.au 


\title{
Ethnically diverse transport behaviours: an Australian perspective
}

\begin{abstract}
Rates of car ownership in Australia are among the highest in the world. Private cars have shaped the urban form of Australian cities and the daily routines of their residents, making it possible to fulfil geographically stretched responsibilities for work, family, and social lives. But the dominance of the private car in Australian lives and landscapes should not be confused with universality. Aggregate, population-wide statistics of car ownership and use mask the fact that not all Australians are equally car dependent. In this paper, we report on the results of a household sustainability survey conducted in metropolitan Sydney and Wollongong. Overseas-born persons, migrants, and (some) ethnic minority groups were found to own fewer cars - and to use them less - than their Anglo-Australian and Australianborn counterparts. These differences were not attributable to socio-economic or demographic factors. Our findings, which point towards the existence of diverse cultures of transport within the Australian population, are significant for transport planning and policymaking. Given profound concerns about the environmental implications of car use, the environmentally (more) sustainable transport behaviours of ethnic minorities and migrants should be supported. A shift in research focus away from the most cardependent groups in Australian society may also be more widely instructive. The transport practices, experiences, and strategies of those who own and drive cars at below-average rates may indeed contribute practical lessons to inform planning for more environmentally sustainable transport futures.
\end{abstract}

\section{Keywords}

australian, behaviours, transport, perspective, diverse, ethnically

\section{Disciplines}

Education | Social and Behavioral Sciences

\section{Publication Details}

Klocker, N., Toole, S., Tindale, A. \& Kerr, S. (2015). Ethnically diverse transport behaviours: an Australian perspective. Geographical Research, 53 (4), 393-405. 


\title{
Klocker, N., Toole, S., Tindale, A. and Kerr, S-M. (2015) 'Ethnically diverse
} transport behaviours: an Australian perspective', Geographical Research53(4): 393-405

\author{
Corresponding author \\ Dr Natascha KLOCKER \\ Senior Lecturer \\ Department of Geography \& Sustainable Communities \\ University of Wollongong \\ NSW 2522 \\ natascha_klocker@uow.edu.au
}

\begin{abstract}
Rates of car ownership in Australia are amongst the highest in the world. Private cars have shaped the urban form of Australian cities and the daily routines of their residents, making it possible to fulfil geographically-stretched responsibilities for work, family and social lives. But the dominance of the private car in Australian lives and landscapes should not be confused with universality. Aggregate, population-wide statistics of car ownership and use mask the fact that not all Australians are equally car-dependent. In this paper, we report on the results of a household sustainability survey conducted in metropolitan Sydney and Wollongong. Overseas-born persons, migrants and (some) ethnic minority groups were found to own fewer cars - and to use them less - than their Anglo-Australian and Australian-born counterparts. These differences were not attributable to socio-economic or demographic factors. Our findings, which point towards the existence of diverse cultures of transport within the Australian population, are significant for transport planning and policymaking. Given profound concerns about the environmental implications of car use, the environmentally (more) sustainable transport behaviours of ethnic minorities and migrants should be supported. A shift in research focus away from the most car-dependent groups in Australian society may also be more widely instructive. The transport practices, experiences and strategies of those who own and drive cars at below-average rates may indeed contribute practical lessons to inform planning for more environmentally sustainable transport futures.
\end{abstract}

Keywords: transport, car dependence, automobility, ethnic minorities, migration, sustainability 


\section{Introduction}

Car Nation was the resolute title of a recent report on Australians’ patterns of car ownership and use (Australian Bureau of Statistics (ABS) 2013a). Australia has been described as a 'nation of proud car owners' (Dowling \& Simpson 2013, p. 421) embroiled in a 'love affair’ with the private car and the lifestyles it enables (Waitt \& Harada 2012, p. 3317). Here, as in other western societies of automobility ${ }^{1}$, cars are considered essential for an ‘appropriate citizenship of mobility’ (Urry 2006, p. 18). They also do important identity work: cars are bound up in notions of freedom, masculinity and national identity, and equally in caring roles and ideals of good parenting (Dowling 2000; Dowling and Simpson 2013). They shape 'not only the way we live but who we are' (Redshaw 2006, p. 75). Yet the environmental implications of car dependence are known to be profound. Transport accounted for 17 per cent of Australia's total greenhouse gas emissions in 2012. Passenger cars were the largest single source, contributing almost half (46.4\%) of this figure (Australian Government 2013). Indirect carbon emissions - embodied in each car’s physical form via manufacture and construction processes (Chester and Horvath 2009) - are also significant, rivalling direct tailpipe emissions over a lifetime of $u^{2} e^{2}$ (Berners-Lee 2010). High rates of car ownership are thus environmentally problematic irrespective of how many kilometres those cars are ultimately driven.

In 2013, Australia’s passenger vehicle fleet ${ }^{3}$ was comprised of 13.0 million vehicles (568 per 1000 persons), up from 1.4 million in 1955 (153 per 1000 persons; ABS 2013a, 2013b). The respective figures for Sydney and Wollongong in 2011/12 were 579 and 649 passenger vehicles per 1000 persons (Bureau of Transport Statistics (BTS) 2013a). Vehicle ownership has outstripped population growth in Sydney: while the resident population increased by 12 per cent between 2001 and 2011, the number of private vehicles climbed by 24 per cent to more than 2.6 million (BTS 2013a). High rates of private car ownership are matched by high rates of private car use. In Sydney, 68.1 per cent of all weekday trips were undertaken by passenger car in 2011/12, as were 76.0 per 
cent of those in Wollongong (BTS 2013b). Such car dependence has been attributed to an extensive program of motorway investment, persistent 'institutional and political support for automobiles as the dominant mode of urban travel' (Dodson et al. 2006:434: Mees and Groenhart 2012), and ‘an entrenched culture of poor public transport management' (Mees et al. 2007:15). For householders, cars are often considered essential to manage complicated daily routines that balance desynchronised, geographically-stretched and competing demands.

Much research attention has focused on the transport behaviours of those Australians who own cars and use them extensively. In this paper, we draw attention away from the factors that make car dependence so difficult to unsettle, and focus instead on identifying Australians whose lives do not neatly adhere to the automobility script. Our research identifies fissures in the logic of automobility by being attentive to the transport behaviours of migrants and ethnic minorities ${ }^{4}$. We do so using data generated by the 'Diverse Cultures, Diverse Households' survey, conducted in metropolitan Sydney and Wollongong in 2012. Our data show that the logic of car dependence only accounts for the transport behaviours of some Australians. When immigration and ethnic diversity are taken together with other points of fissure identified in the literature - including the significance of information technologies in reducing the need for car journeys; the declining interest in cars amongst younger generations; and the rise of alternative ways of relating to motor vehicles via carsharing networks (Dowling and Simpson 2013; Millard-Ball and Shipper 2011; Goodwin 2010) - it becomes evident that broader social, demographic and cultural shifts may play an important role in loosening the private car's grip over everyday life. These possibilities require further exploration, particularly because environmental awareness and concern have had minimal success in decreasing car use (ABS 2013a; Waitt and Harada 2012). In the following sections, we first review existing research into ethnically diverse transport behaviours, before presenting empirical evidence of such trends in an Australian context. We conclude that migrants and specific ethnic minority groups have more environmentally sustainable transport behaviours than Australian-born and Anglo-Australian 
persons - that is, transport behaviours which depend less on private motor vehicles and more on public and/or active forms of transport. We urge greater consideration of ethnic diversity in transport policy and research, including efforts to uncover the role of cultural factors in shaping these trends.

\section{Diversifying ethnicity in Australian transport policy and research}

When ethnic diversity is not explicitly taken into account in transport policy and research, the resultant aggregate statistics necessarily reflect the norms of the numerically dominant AngloAustralian ethnic majority. Yet, at the 2011 Census, 26 per cent of all Australians (and 39\% of Sydney residents) were first-generation migrants (ABS 2014). A similar proportion had overseasborn parents (ABS 2014). The ethnic mix of the Australian population has changed substantially over time: by 2011 only 57.7 per cent of residents claimed solely Anglo-Celtic or Anglo-Saxon ancestry (ABS 2012). A large proportion of recent migrants have come from Asian countries including India, China, the Philippines, Sri Lanka, Malaysia, the Republic of Korea and Vietnam

(Department of Immigration and Citizenship 2013) ${ }^{5}$. Within this context of population diversity, Shove's (1998:11) call to 'disaggregate 'car dependency'” is particularly pertinent. Expectations of mobility vary between countries, according to distinctive national cultures of automobility (Edensor 2004, Sheller 2004). They also vary within populations - particularly in immigrant societies.

Researchers in the US (Blumenberg \& Shiki 2007; Bohon et al. 2008; Chatman \& Klein 2009; Douma 2004; Golub et al. 2013; Grengs 2010; Liu \& Schachter 2004; Lovejoy \& Handy 2008; Modarres 2009, 2013; Tal \& Handy 2010), Canada (Heisz \& Schellenberg 2004), UK (Preston \& Rajé 2007; Rajé 2007) and Norway (Uteng 2006) have reported that non-whites in general - and migrants in particular - own fewer cars and use public transport more regularly than whites and native-born populations. In the US, rates of car ownership are particularly low amongst African Americans (Blumenberg 2008; Grengs 2010). Migrants - particularly Latino/as - have also reported 
below-average rates of car ownership, alongside a propensity for car-sharing and carpooling (Bohon et al. 2008; Lovejoy \& Handy 2008; Tal \& Handy 2010). The distinctive transport behaviours of ethnic minorities and migrants have often been attributed to socio-economic disadvantage and marginalisation: a lack of financial capacity to purchase, maintain and fuel a private car (Bohon et al. 2008; Grengs 2010; Uteng 2006). Other studies have drawn attention to the significance of cultural factors and transport preferences, shaped by experiences in migrants' countries of origin (Chatman \& Klein 2009, Douma 2004). These perspectives, which are not mutually exclusive, are outlined on the following pages.

\section{Making sense of diverse transport behaviours: a social exclusion perspective}

Mobility is ‘a resource to which not everyone has an equal relationship’ (Skeggs 2004, p. 49; Uteng 2006). Diverse mobilities are a product of inequitable social relations and power inequalities and are in turn productive of these inequalities (Binnie et al. 2007; Cresswell 2010; Sheller \& Urry 2000). When cities are ‘deliberately designed for cars’ (Grengs 2010, p. 43), being dependent upon public transport is a distinct disadvantage: a cause and consequence of social exclusion. For ethnic minorities and migrants, this disadvantage is compounded by poor public transport provision in the neighbourhoods where they reside (Golub et al. 2013; Heisz \& Schellenberg 2004; Hine \& Mitchell 2001; Karner \& Niemeier 2013; Rajé 2007; Tal \& Handy 2010). Under such circumstances, the inability to afford a reliable car results in 'foregone opportunities’ (Lovejoy \& Handy 2008, p. 604). Car-less-ness can be a result of socio-economic disadvantage. It also - in turn - hinders access to important societal resources (employment, education, healthcare and social networks) and thus reinforces residential segregation, isolation and socio-economic disadvantage over time (Hine \& Mitchell 2001; Lovejoy and Handy 2008; Rajé 2004, 2007; Uteng 2006). For migrants, a lack of access to private transport can encumber the settlement process, acting as a 'bottleneck to adjustment' and socioeconomic mobility - with potentially inter-generational effects (Bohon et al. 2008, p. 288; Andersson et al. 2012). Conversely, unfettered access to cars has been identified as a 
'strong and statistically significant predictor of employment' across a range of ethnic groups (Blumenberg 2008, p. 38). These findings have contributed to an environmentally perverse conclusion among a number of studies conducted in the U.S. and Europe: socio-economically disadvantaged ethnic minority and migrant households will be best assisted by policies that increase their access to private cars - for instance, through government subsidies or low-interest loans (Blumenberg 2008; Bohon et al. 2008; Grengs 2010; Uteng 2006). Rather than challenging poor public transport provision, such studies have identified low rates of car ownership as the chief problem to be overcome. The potential to appropriately support ethnic minorities and migrants' to sustain environmentally beneficial transport practices (and, for some, preferences) has been overlooked.

\section{Making sense of diverse transport behaviours: a cultural perspective}

For low-income migrants, public transport may be the only economically viable means of commuting to work. For others, cultural differences and habits formed in countries of birth may be the determining factor behind post-migration transport choices and experiences (Blumenberg 2008; Liu \& Schacter 2004; Modarres 2013). In many countries, 'ownership of a car is unthinkable for the great majority of people' (Edensor 2004, p. 115). Migrants from such regions often report belowaverage rates of private car use (Chatman \& Klein 2009; Heisz \& Schellenberg 2004). Public transport supply also has an important bearing over public transport use (Mees 2000); migrants who come from cities with efficient public transport networks may bring a habitual disposition towards using public transport with them. In the US, Tal and Handy (2010) found that East Asian migrants were more likely to use public transport and travelled fewer vehicle miles per person than other migrant groups and the general population, even after controlling for household size and income. Similarly, Modarres (2009, 2013) found that income differences did not adequately account for above-average rates of public transport use amongst Latino/a migrants. While higher income Latino/as used cars more frequently than their lower-income counterparts, they used public 
transport more than the native-born US population at every income level. This is likely attributable to an expressed preference for 'social' types of travel 'common among their culture' (Douma 2004, p. 38). The 'transport legacy' that new migrants bring with them may work either for or against public transport use post-migration (Rajé 2004, p. 47). In the case of West Indian migrants to the UK, Rajé (2004, p. 47) observed a distrust of public transport related to the 'highly dangerous circumstances of public transport in Jamaica and unreliability elsewhere in the Caribbean'. This has resulted in a 'form of cultural path dependency', with West Indians aspiring to own cars as quickly as possible post-migration (Rajé 2004, p. 47). In the remainder of this paper we take an initial step towards uncovering ethnically diverse transport behaviours in Australia, based on analyses of Census data and our own household sustainability survey. The next important step, which is beyond the scope of this quantitative paper, is to conduct ethnographic research to explain and further explore the statistical differences reported upon here.

\section{Methods}

In 2011, the Australian Census recorded information on the number of registered Personal Motor Vehicles (PMVs) per dwelling (excluding motorbikes and motor scooters) and method of travel to work on Tuesday 9 August 2011, for household members aged 15 and over. Data pertaining to these Census questions were disaggregated according to ethnicity and migration status for residents of the Sydney and Wollongong Significant Urban Areas (SUAs). 'Method of travel to work' data were generated using ABS TableBuilder. Data on the number of PMVs per dwelling, according to ethnicity and migration status, were generated using the Expanded Census Sample File (CSF ${ }^{6}$ ).

Our Diverse Cultures, Diverse Households survey included 15 questions pertaining specifically to transport behaviours and values. Hardcopy questionnaires were produced in six languages (English, Simplified Chinese, Vietnamese, Filipino, Hindi and Arabic) and distributed by post to 3000 households in Sydney and Wollongong in $2012^{7}$. These language groups represent large and 
growing migrant communities in Australia. Because random sampling typically yields insufficient representation of ethnic minority groups, a targeted surname-based mail-out approach was used (Tjam 2001). Appropriate surnames were selected with assistance from relevant migrant community organisations, and the telephone directory was used to identify 500 households for each linguistic group. A response rate of 9.2 per cent was achieved using this method (275 useable surveys). An online version of the survey was prepared in six languages: English, Simplified Chinese, Traditional Chinese, Vietnamese, Filipino and Hindi. Arabic was excluded because right-to-left script was not adequately supported by the online survey host. Information about the online survey was distributed through the NSW Community Relations Commission (CRC) email list-serve. Using this method, 303 useable surveys were received from Sydney and Wollongong residents. The total number of completed surveys (hardcopy and online) was 578. The sample population of our survey is not representative of the broader population of Wollongong and Sydney: individuals from ethnic minority backgrounds are over-represented. This is an artefact of the targeted sampling approach, designed to obtain an adequate number of responses from ethnic minority households (for the purposes of statistical analysis) without exceeding the project budget.

Ethnicity and migration status were determined according to survey respondents' country of birth and self-reported ethnicity. Respondents were broadly grouped into the categories Australian-born $(n=229)$ and overseas-born ( $n=325)$. International studies have identified a 'tipping point' (5 to 10 years post-migration) after which the travel behaviours of migrants converge with the native-born population (Blumenberg \& Shiki 2007; Heisz \& Schellenberg 2004; Modarres 2009, 2013; Tal \& Handy 2010). Our survey data analysis divided migrants into two categories based on duration of residence: 10 years or less $(n=70)$ and 11 years or more $(n=247)$. Most respondents described their ethnicity using national-level identifiers (e.g. Vietnamese). These responses were combined into regional categories based on the ABS Standard Classification of Cultural and Ethnic Groups. Four groups had a sufficient number of respondents to allow for statistical analysis: Anglo-Australian ( $\mathrm{n}=$ 
180); North-East Asian ( $\mathrm{n}=97)$; South-East Asian ( $\mathrm{n}=58)$; and South and Central Asian ( $\mathrm{n}=53)$.

Finer-grained groupings were not possible given the sample size. Each regional group included both overseas- and Australian-born persons of the respective ethnicity.

Statistical analyses were conducted using SPSS version 22. Cross-tabulations were performed to account for differences in transport behaviours and values according to ethnicity and migration status. Statistical significance was tested with Pearson's chi-squared test at $5 \%(0.05)$ and $1 \%(0.01)$ levels of significance. Ordinal regression was used to control for the effects of variables likely to influence the relationship between ethnicity/migration status and the dependent (transport-related) variables such as demographic characteristics (gender, generation, income, employment status and the presence of dependent children in the home), and place of residence (Sydney/Wollongong). Weekly household income (after tax) was classified as low (\$1-\$799), medium (\$800-\$2499) or high (\$2500-\$4000+); dependent children (aged under 18) were recorded as present or absent for each household. Employment status was categorised as 'employed or studying' or 'not employed or studying'; and respondent generation was classified into four groups: Generation Y (born 19751991), Generation X (1965-1974), Baby Boomers (1945-1965) or Silent Generation (1944 and earlier) (see also Jones and Fox 2009). Logistic regression was used in the case of binary questions or where there was a lack of compliance with the prerequisites of ordinal regression. The effects of these regression analyses on the significance of the relationships observed between ethnicity/migration status and transport patterns are outlined in detail in Table 2, and are discussed below as relevant. Our results are presented in two sections: the first provides an overview of our Census data analysis and the second reports on the findings of our household survey.

\section{Ethnically diverse transport behaviours: the Australian Census}

Our analysis of 2011 Census data revealed that rates of PMV ownership in Sydney and Wollongong differed according to ethnicity and migration status. Overseas-born persons were at least twice as 
likely as Australian-born persons to live in households without a PMV, and were less likely to report living in a household with multiple PMVs (Table 1). Duration of residence was an important factor, with those who had migrated within the five years preceding the Census reporting the lowest rates of household PMV ownership. Ethnicity was also important: persons of North-East Asian ancestry were most likely to live in households without a PMV in both Sydney and Wollongong (13.2\% and 17.3\% respectively; Table 1). In both cities, individuals of South and Central Asian ancestry were most likely to live in single PMV households (40.6\% and 55.1\% respectively), suggesting a heightened propensity to share vehicles between household members. Those of AngloAustralian ancestry were most likely to report living in multiple PMV households (65.7\% and $66.5 \%$ respectively; Table 1$)$.

\section{[SEE TABLE 1 INCLUDED AT THE END OF THE DOCUMENT]}

On the whole, residents of Wollongong were more dependent on PMVs for the journey to work than Sydney residents (Table 1). In Sydney, overseas-born persons were more likely to report travelling to work without using a PMV than Australian-born persons (35.1\% versus 24.8\%). In both cities, the propensity to travel to work solely by PMV increased in a linear fashion with duration of residence in Australia. Migrants who had lived in Australia for more than 20 years had rates of PMV use on par with the Australian-born (Table 1). In the first five years post-migration, 57.7 per cent of migrants living in Sydney, and 34.9 per cent of those in Wollongong, did not use PMVs for the journey to work, more than double the rate of the Australian-born. With regards to ethnicity, in both Sydney and Wollongong persons of Asian ancestry were most likely to report not using PMVs for the journey to work. Sydney residents of North-West European ancestry also displayed a high propensity so make the journey to work without PMVs - the reasons for which cannot be ascertained on the basis of Census data. More than 40 per cent of North-East Asian and South and Central Asian persons living in Sydney reported not using a PMV for the work commute 
(Table 1). These groups were also the most likely to travel to work without a PMV in Wollongong, although the rates were lower ( $27.2 \%$ and $23.8 \%$ respectively). In both cities, the propensity to travel to work by 'PMV only’ was 15 to 20 percentage points higher amongst Anglo-Australians than North-East Asian and South and Central Asian persons. In Sydney, the group most likely to travel to work by 'PMV only' was North African and Middle Eastern, and in Wollongong it was those of South-East European ancestry (Table 1). Overall, the Census data are indicative of lower rates of car ownership and use amongst overseas-born persons and individuals of Asian ancestry. While they offer only a limited insight into overall transport behaviours and preferences, they are based on a population-wide sample and thus provide an important foundation for interpreting our own survey data.

\section{Ethnically diverse transport behaviours: the Diverse Cultures, Diverse Households survey}

Overseas-born survey respondents reported being less car-dependent and owning fewer cars than Australian-born respondents. The propensity to own and use cars also differed considerably according to ethnicity. As shown in Table 2, the majority of these significant differences held true after controlling for demographic factors (gender, generation, income, employment status and presence of dependent children), as well as city of residence (Sydney or Wollongong). These findings, discussed in detail on the following pages, suggest that cultural factors may exert an important influence on transport behaviours.

\section{[SEE TABLE 2 INCLUDED AT THE END OF THE DOCUMENT]}

We compared the number of PMVs per adult household member across the survey population (Table 2). Our findings mirror the trends observed in the Census analysis presented above. Australian-born and Anglo-Australian respondents typically owned at least one vehicle per adult household member. Overseas-born respondents were significantly more likely to share vehicles 
amongst household members, with 64.1 per cent reporting that their household owned less than one PMV per adult (compared to 38.9\% of the Australian-born). The propensity to share PMVs decreased with duration of residence in Australia. Of those respondents who had lived in Australia for ten years or less, 80.3 per cent reported having less than one PMV per adult, compared to 59.4 per cent of those who had lived in Australia for 11 years or more. North-East Asian and South and Central Asian respondents were particularly likely to share PMVs amongst adult household members: three-quarters of respondents in both groups did so. These significant differences in PMV ownership remained after controlling for demographic characteristics and city of residence (Table 2). Respondents were also asked to indicate what types of PMVs they owned. Almost one-quarter of North-East Asian respondents lived in households that did not own any PMVs. Australian-born persons were significantly more likely to own large, fuel-intensive vehicles (4WDs, vans and utes) than overseas-born persons (38.9\% versus 24.4\%; Table 2). North-East Asian respondents were the least likely to own large vehicles - only 14.4 per cent reported living in a household that owned such a vehicle, significantly less than the comparable figure for Anglo-Australian respondents (37.2\%).

Survey respondents’ PMV-use was explored via weekly household petrol expenditure, per adult. Australian-born and Anglo-Australian respondents reported significantly higher fuel expenditure than other groups, with around one-quarter spending \$50 or more per adult, per week. Migrants’ duration of residence in Australia affected petrol expenditure: only 6.5 per cent of the more recent migrants (10 years or less) reported spending such a large sum. North-East Asian and South and Central Asian respondents reported significantly lower petrol expenditure than Anglo-Australians. These differences remained significant after controlling for demographic factors, thus income did not appear to be the determining factor (Table 2). 
The survey also inquired about respondents' typical mode of transport for various trip types. The most sizeable differences were recorded for the work/study trip. Overseas-born persons, migrants who had lived in Australia for ten years or less and North-East Asian respondents were significantly less likely (than Australian-born and Anglo-Australian respondents) to report depending solely on a PMV for the work/study trip (see 'PMV only', Table 2). North-East Asians were significantly more likely to report relying on public or active transport than Anglo-Australians (36.6\% versus 22.5\%). One-third of South and Central Asian respondents also reported eschewing PMVs for the work/study trip; while South-East Asian respondents were most likely to use PMVs in combination with public/active transport (34.6\% did so, compared to $12.0 \%$ of Anglo-Australians). Shorter-term migrants (10 years or less) were almost half as likely as Australian-born respondents to travel to work/study by PMV only (36.5\% versus 67.2\%). As shown in Table 2, reliance on PMVs for the work/study trip increased with duration of residence. The significant differences discussed above (for overseas-born persons, short-term migrants and North-East Asians) remained after controlling for demographic factors and city of residence (Table 2). Differences in mode of transport were less pronounced - and in most instances, non-significant - for other trip-types, particularly social and recreational trips (Table 2). However, shorter-term migrants (10 years or less) were significantly more likely than the Australian-born to grocery shop without a car (27.3\% versus $12.7 \%)$. NorthEast Asian respondents were also significantly more likely than Anglo-Australians to report grocery shopping using active or public transport (33.3\% versus 10.6\%).

The survey also explored respondents’ propensity to adopt strategies to reduce car use (Table 2). Overseas-born persons were significantly more likely than the Australian-born to report always using the following strategies: combining car trips to save petrol (32.7\% versus $18.6 \%)$; walking or riding for short trips (26.5\% versus 13.6\%); and using public transport when possible (25.8\% versus 9.8\%). Even longer-term migrants (more than 10 years) were almost twice-as-likely to report always combining car trips and walking or riding for short trips than the Australian-born. Both 
longer-term and more recent migrants (10 years or less) were significantly more likely than the Australia-born to report always using public transport when possible. In addition, North-East Asian respondents were significantly more likely to always combine car trips to save petrol $(41.1 \%$ versus 16.9\% for Anglo-Australians); North-East Asian and South and Central Asian respondents were significantly more likely to always walk or ride for short trips (30.0\% and $32.7 \%$ versus $12.6 \%$ for Anglo-Australians); and North-East Asian, South-East Asian and South and Central Asian respondents were significantly more likely to report always using public transport when possible (27.0\%, 32.1\% and 32.0\% versus 9.7\% for Anglo-Australians). These differences remained significant after controlling for demographic factors and city of residence. Reported rates of carpooling were low across the entire sample (Table 2).

Finally, survey respondents were asked to indicate how strongly they agreed or disagreed with four attitudinal statements pertaining to PMVs and public transport (Table 2). Significant differences only emerged in relation to the first of these statements - 'People in my household are very dependent on motor vehicles'. Respondents' self-assessments of car dependence accurately reflected the behavioural data discussed above. Overseas-born persons, shorter-term migrants, North-East Asian, South-East Asian and South and Central Asian respondents, were significantly more likely to disagree with the statement on car dependence than Australian-born respondents and Anglo-Australians. Differences in relation to the remaining three attitudinal questions were nonsignificant. On aggregate, the survey respondents were substantially more likely to report being concerned with fuel costs than with the environmental impacts of driving; and all groups (with the exception of recent migrants) were similarly likely to view public transport as an option of last resort (Table 2). 


\section{What drives ethnically diverse travel behaviours in Sydney and Wollongong?}

Our survey results suggest that the differences in transport behaviours observed in our sample population - according to ethnicity and migration status - are not directly attributable to demographic factors. Respondent gender and generation, employment status, household income, the presence of dependent children and city of residence did not account for the reduced propensity of overseas-born persons, recent migrants and specific ethnic groups (particularly North-East Asian and South and Central Asian persons) to own and use cars. Our data suggest that below-average rates of car ownership and use amongst (some) ethnic minorities and migrants are not a result of socio-economic deprivation. The deprivation model often used to explain transport discrepancies in the US context does not neatly apply in Australia. Our results point towards the potential significance of cultural factors - and experiences of transport in countries of origin - in shaping transport behaviours. Previous studies have shown that immigrants' choices of residential location are 'based in part on how they prefer and expect to travel on a daily basis' (Chatman and Klein 2009:324). In Melbourne, Australia, Levin (2012) found that Chinese immigrants intentionally chose to live in neighbourhoods with good access to public transport (alongside educational and shopping opportunities). While Australian cities are not highly segregated along ethnic lines, distinct ethnic residential geographies are apparent for some ethnic groups (Johnston et al. 2007). These are a function of both choice and constraint. The links between ethnicity, place of residence and cultural preferences (for both particular neighbourhood types and particular transport modes) require further investigation.

Our results confound common perceptions regarding the influence of gender and household composition on car ownership and use. Analyses of gender and transport have shown that women use public transport more than men (Bureau of Transport Statistics 2013a; Hanson 2010). Yet in our study, some of the groups with the highest proportions of male respondents (South and Central Asians, overseas-born persons and recent migrants ${ }^{8}$ ) reported below-average rates of car ownership 
and use. Furthermore, previous studies have noted that private cars are needed to help parents juggle complex daily routines with dependent children in tow (Dowling 2000). Yet in our study, the groups who most commonly had dependent children living in the home (overseas-born persons, recent migrants, South and Central Asians and North-East Asians ${ }^{9}$ ); were also least likely to report high rates of car ownership and use (Table 2). The strategies that these groups deploy to juggle multiple responsibilities for parenting and paid work - with no (or fewer) cars - are ripe for further exploration.

\section{Concluding remarks}

Oft-repeated claims of Australians’ car dependence are too simplistic. The description of Australia as a 'car nation', with which we began this paper, only reflects the practices of some Australians. Many Australians (in our case, overseas-born persons, recent migrants, and Australians of NorthEast Asian and South and Central Asian ethnicity) have more environmentally sustainable transport behaviours than this label suggests. These groups own and use cars at significantly reduced rates, but their practices are not attributable to socio-economic disadvantage. However, quantitative survey instruments (such as ours) can only reveal so much; and we do not wish to draw conclusions that essentialise ethnicity. Ethnographic research is needed to explore the role of cultural factors in contributing to transport choices, and how these intersect with other aspects of identity.

Our own findings ultimately raise more questions than answers. For instance, do some migrants and ethnic minorities experience and value private motor vehicles (and indeed public transport) differently to Australian-born and Anglo-Australian persons? Are migrants from countries in which public transport use is ubiquitous less prone to conceive of public transport as 'slow, impracticable, inflexible, fragmented and inconvenient' (Gibson et al. 2013, p. 137; Böhm et al. 2006), or indeed as 'disgusting' (Waitt and Harada 2012)? Does this affect their willingness to use public transport and tolerances and competencies in negotiating its rhythms and codes of conduct (Binnie et al. 
2007; Bissell 2009; Butcher 2011; Symes 2007)? If ‘[r]esisting the coercive features of automobility' is indeed 'nearly impossible' (Sheller and Urry 2000:749), then how and why do some migrants and ethnic minorities appear to be less entangled in its web? How do those ethnic minorities and migrants who are less car-dependent manage to juggle their competing daily responsibilities in contemporary Australian cities? And how do migrants’ perceptions and expectations of transport change over time as they face the realities of Australia’s transport networks and urban forms, alongside pressures to adopt the everyday practices of ‘Australian’ car culture? Greater efforts are needed to 'learn the shape' of ethnic minorities and migrants' transport journeys and experiences, by including their voices in transport research (Rajé 2004: 49). Research is also needed to better understand how driving is 'practised, performed, and given meaning in the lives of different people' (Redshaw 2006, p. 77); and how cars are valued (or not) in a 'variety of locally lived worlds’ (Frederick \& Stefanoff 2011, p. 5).

The focus in policy, planning and academic arenas has often been on the most car-dependent groups in our society, rather than the least. This approach needs to be challenged as it may solidify and reinforce expectations of car dependence, and close off opportunities to locate and understand alternatives. It may also ultimately push those who already use public transport, to shift towards cars over time. Our findings suggest that the logic of automobility is not immutable (Goodwin 2010). There are 'contestations, contradictions and multiplicities at play' that point towards different ways of using cars (Dowling \& Simpson 2013, p. 426; Hanson 2010). Greater insights into these differences need to be garnered via careful qualitative research into ethnically diverse transport practices. Such findings could in turn be used to plan for more sustainable transport futures. Given the profound environmental implications of car ownership and use, future research should explore how the environmentally (more) sustainable transport behaviours of some ethnic minorities and migrants can be supported and sustained by transport policymakers and planners (Modarres 2009, 2013). We are not suggesting that transport policies and urban planning strategies 
be designed to target specific ethnic groups - but that they become more receptive to diverse perspectives and needs. Transport policies that do not take ethnic diversity into account reinforce the status quo, resulting in the perpetuation of the ethnic majority's norms and preferences (Rajé 2004). This approach is limited and limiting. Following Goodwin (2010, p. 75), it important to 'scratch the surface' of the structure of automobility to uncover 'instances of (and opportunities for) human ingenuity, investigation, and re-imagination'. Those migrants and ethnic minorities 'who are not yet captives’ of Australia’s car-dependent norms (Tal \& Handy 2010, p. 85) could play a valuable role as agents of change. In their transport practices and experiences, there may reside practical lessons that are more widely instructive for sustainable transport planning.

\section{Acknowledgements \& Source of funding}

This research was supported by a University of Wollongong URC Small Grant. 


\section{Notes}

${ }^{1}$ Automobility has been described as a 'state in which the petroleum-fuelled private car rules the spaces and rhythms of everyday life' (Dowling \& Simpson 2013, p. 423) and 'reorganises how people negotiate the opportunities for, and constraints upon, work, family life, leisure and pleasure’ (Sheller \& Urry 2000, p. 738).

${ }^{2} \mathrm{CO}_{2} \mathrm{e}$ (carbon dioxide equivalent) refers to the total climate change impact of all greenhouse gases caused by an activity/thing, expressed in terms of the amount of carbon dioxide that would be needed to have the same impact. Depending on size, the embodied emissions of a new car range from 6 to 35 tonnes $\mathrm{CO}_{2} \mathrm{e}, 6$ tonnes for a Citroen $\mathrm{C} 1,17$ tonnes for a Ford Mondeo and 35 tonnes for a Land Rover Discovery (Berners-Lee 2010).

${ }^{3}$ The ABS (2013a, p. 25) has defined passenger vehicles as: 'Motor vehicles constructed primarily for the carriage of persons and containing up to nine seats (including the driver's seat). This category includes cars, station wagons, fourwheel drive passenger vehicles and forward-control passenger vehicles.' It does not include motorcycles, buses, campervans, trucks or light commercial vehicles.

${ }^{4}$ We use the term ethnic minority to refer to individuals who are not of part of the (white, mainstream) Anglo-European ethnic majority in Australia. We use the term migrant to refer specifically to first generation migrants (i.e. overseasborn persons).

${ }^{5}$ These were all amongst the Top 10 source countries of migrants to Australia in 2011/12 (Department of Immigration and Citizenship 2013).

${ }^{6}$ The CSF provides access to data from a 5\% random sample of all households. It allows data pertaining to persons and their dwellings to be analysed together.

${ }^{7}$ The survey was initial intended for Wollongong households only. Due to Wollongong's relatively small population, the survey was extended into Sydney in order to ensure that an adequate number of individuals from ethnic minority backgrounds could be reached.

${ }^{8}$ South and Central Asians (73.5\% of respondents were male), overseas-born persons (41.1\% male) and recent migrants (45.5\% male); compared to Australian-born (28.1\% male) and Anglo-Australian (30.7\% male).

${ }^{9}$ Overseas-born respondents (38.2\% had dependent children in the home); recent migrants (57.1\%); South and Central Asians (47.2\%); North-East Asians (37.1\%); compared to Australian-born (29.3\%) and Anglo-Australians (23.9\%). 


\section{References}

Andersson E, Malmberg B, Östh J (2012) Travel-to-school distances in Sweden 2000-2006:

changing school geography with equality implications. Journal of Transport Geography 23, 35-43. Australian Bureau of Statistics (2012), Reflecting a Nation: Stories from the 2011 Census, 20122013, Cat.No. 2071.0, ABS, Canberra.

Australian Bureau of Statistics (2013a) Australian Social Trends, July 2013, Car Nation, Cat.No. 4102.0, ABS, Canberra.

Australian Bureau of Statistics (2013b) Motor Vehicle Census, Australia, 31 Jan 2013. Cat. No. 9309.0, ABS, Canberra.

Australian Bureau of Statistics (2014) Australian Social Trends, Cat. No. 4102.0, ABS, Canberra. Australian Government (2013). Australian National Greenhouse Accounts, Quarterly Update of Australia’s National Greenhouse Gas Inventory, December Quarter 2012. Published by the Department of Industry, Innovation, Climate Change, Science, Research and Tertiary Education, Commonwealth of Australia. http://www.climatechange.gov.au/climate-change/greenhouse-gasmeasurement-and-reporting/tracking-australias-greenhouse-gas-emissio-0/quarterly-updateaustralias-national-greenhouse-gas-inventory-march-13 (Accessed 4.5.15)

Berners-Lee M (2010) How Bad are Bananas? The Carbon Footprint of Nearly Everything. Profile Books, London.

Binnie J, Edensor T, Holloway J, Millington S, Young C (2007) Mundane mobilities, banal travels. Social \& Cultural Geography 82, 165-174.

Bissell D (2009) Conceptualising differently-mobile passengers: geographies of everyday encumbrance in the railway station. Social \& Cultural Geography 10, 173-195.

Blumenberg E, Shiki K (2007) Transportation assimilation: immigrants, race and ethnicity, and mode choice. Transportation Research Board Annual Meeting, Paper \#07-2475; http://trid.trb.org/view.aspx?id=802238 (accessed 24.2.14). 
Böhm S, Jones C, Land C, Paterson M (2006) Against Automobility: Social Scientific Analyses of a Global Phenomenon. Blackwell, Oxford.

Bohon S, Stamps K, Atiles J (2008) Transport and migrant adjustment in Georgia. Population Research and Policy Review 27, 273-291.

Bureau of Transport Statistics (2013a). 2011/12 Household Travel Survey. Key Indicators. New South Wales Government, Sydney. http://www.bts.nsw.gov.au/Publications/Reports/default.aspx (accessed 7.12.14)

Bureau of Transport Statistics (2013b). 2011/12 Household Travel Survey. Summary Report 2013 Release. New South Wales Government, Sydney http://www.bts.nsw.gov.au/Publications/Reports/default.aspx (accessed 7.12.14) Butcher M (2011) Cultures of commuting: the mobile negotiation of space and subjectivity on Delhi’s metro. Mobilities 6, 237-254.

Chatman D, Klein N (2009) Immigrants and travel demand in the United States: implications for transportation policy and future research. Public Works Management Policy 13, 312-325.

Chester M, Horvath A (2009). Environmental assessment of passenger transportation should include infrastructure and supply chains. Environmental Research Letters 4, 1-8.

Cresswell T (2010) Towards a politics of mobility. Environment and Planning D: Society and Space 28, 17-31.

Department of Immigration and Citizenship (2013) Australian migration trends 2011-2012. Commonwealth of Australia, Canberra.

Dodson, J., Buchanan, N., Gleeson, B. and Sipe, N., (2006) Investigating the social dimensions of transport disadvantage - I. Towards new concepts and methods. Urban Policy and Research 24, 433-453.

Douma F (2004) Using ITS to Better Serve Diverse Populations. Report prepared for Minnesota Department of Transportation Research Services Section, Minnesota. 
Dowling R (2000) Cultures of mothering and car use in suburban Sydney: a preliminary investigation. Geoforum 31, 345-353.

Dowling R, Simpson C (2013) ‘Shift - the way you move’: reconstituting automobility. Continuum: Journal of Media \& Cultural Studies 27, 421-433.

Edensor T (2004) Automobility and national identity: representation, geography and driving practice. Theory, Culture \& Society 21, 101-120.

Frederick U, Stefanoff L (2011) Emerging perspectives on automobilities in non-urban Australia: a context for Cruising Country. Humanities Research XVII, 1-16.

Gibson C, Farbotko C, Gill N, Head L, Waitt G (2013) Household sustainability: challenges and dilemmas in everyday life. Edward Elgar, Cheltenham.

Golub A, Marcantonio R, Sanchez T (2013) Race, space and struggles for mobility: transportation impacts on African Americans in Oakland and the East Bay. Urban Geography 34, 699-728.

Goodwin K (2010) Reconstructing automobility: the making and breaking of modern transportation. Global Environmental Politics 10, 60-78.

Grengs J (2010) Job accessibility and the modal mismatch in Detroit. Journal of Transport Geography 18, 42-54.

Hanson S (2010) Gender and mobility: new approaches for informing sustainability. Gender, Place \& Culture 17, 5-23.

Heisz A, Schellenberg G (2004) Public transit use among immigrants. Canadian Journal of Urban Research 13, 170-191.

Hine J, Mitchell F (2001) Better for everyone? Travel experiences and transport exclusion. Urban Studies 38, 319-332.

Johnston R, Poulsen M, Forrest, J (2007) The geography of ethnic residential segregation a comparative study of five countries. Annals of the Association of American Geographers 97, 713738. 
Jones S, Fox S (2009). Generations Online in 2009, Pew Internet and American Life Project.

Retrieved from http://pewinternet.org/Reports/2009/Generations-Online-in-2009.aspx (accessed

Karner A, Niemeier D (2013) Civil rights guidance and equity analysis methods for regional transportation plans: critical review of literature and practice. Journal of Transport Geography 33, 126-134.

Levin, I (2012) Chinese migrants in Melbourne and their house choices. Australian Geographer 43, 303-320.

Liu R, Schachter H (2004) Mobility information needs of immigrants with Limited English Proficiency (LEP) in New Jersey. Journal of Immigrant and Refugee Studies 5, 89-108.

Lovejoy K, Handy S (2008) A case for measuring individuals’ access to private-vehicle travel as a matter of degrees: lessons from focus groups with Mexican immigrants in California.

Transportation 35, 601-612.

Mees, P. (2000) A Very Public Solution: Transport in the dispersed city, Melbourne University Press, Melbourne.

Mees, P., Sorupia, E. and Stone, J. (2007) Travel to work in Australian capital cities, 1976-2006: an analysis of census data. Australasian Centre for the Governance and Management of Urban Transport, University of Melbourne.

Mees, P. and Groenhart, L. (2012) 'Transport policy at the crossroads: travel to work in Australian capital cities, 1976-2011', RMIT University, Melbourne.

Millard-Ball, A. and Schipper, L. (2011) Are we reaching peak travel? Trends in passenger transport in eight industrialised countries. Transport Reviews 31, 357-378

Modarres A (2009) Immigrants are 'greening' our cities, how about giving them a break? New Geography. http://www.newgeography.com/content/00958-immigrants-are\%E2\%80\%98greening\%E2\%80\%99-our-cities-how-about-giving-them-a-break (accessed 7.12.14) 
Modarres A (2013) Commuting and energy consumption: toward an equitable transportation policy. Journal of Transport Geography 33, 240-249.

Preston J, Rajé F (2007) Accessibility, mobility and transport-related social exclusion. Journal of Transport Geography 15, 151-160.

Rajé F (2004) Transport, demand management and social inclusion: the need the ethnic perspectives. Ashgate, Hampshire.

Rajé F (2007) The lived experience of transport structure: an exploration of transport’s role in people’s lives. Mobilities 2, 51-74.

Redshaw S (2006) driving cultures: cars, young people and cultural research. Cultural Studies Review 12, 74-89.

Sheller M (2004) Automotive emotions: feeling the car. Theory, Culture \& Society 21, 221-242.

Sheller M, Urry J (2000) The city and the car. International Journal of Urban and Regional Research 24, 737-757.

Shove E (1998) Consuming Automobility: a discussion paper. Project SceneSusTech. Scenarios for a sustainable society: car transport systems and the sociology of embedded technologies.

Employment Research Centre, Trinity College, Dublin.

Skeggs B (2004) Class, Self, Culture. Routledge, London.

Symes C (2007) Coaching and training: an ethnography of student commuting on Sydney’s suburban trains. Mobilities 2, 443-461.

Tal G, Handy S (2010) Travel behaviour of immigrants: an analysis of the 2001 National Household Transportation Survey. Transport Policy 17, 85-93.

Tjam E (2001) How to find Chinese research participants: use of a phonologically based surname search method. Canadian Journal of Public Health 92, 138-142.

Urry J (2006) Inhabiting the car. The Sociological Review 54s1, 17-31.

Uteng T (2006) Mobility: discourses from the non-western immigrant groups in Norway. Mobilities $1,437-464$. 
Waitt G, Harada T (2012) Driving, cities and changing climates. Urban Studies 49, 3307-3325. 
Table 1: PMV ownership and use (Census data)

\begin{tabular}{|c|c|c|c|c|c|c|c|c|c|c|c|c|}
\hline & \multicolumn{6}{|c|}{ No. of PMVs per household $(\%)^{a}$} & \multicolumn{6}{|c|}{ Method of transport to work ${ }^{b}(\%)$} \\
\hline & \multicolumn{2}{|c|}{$\mathbf{0}$} & \multicolumn{2}{|c|}{1} & \multicolumn{2}{|c|}{$2+$} & \multicolumn{2}{|c|}{ PMV Only } & \multicolumn{2}{|c|}{ PMV \& other } & \multicolumn{2}{|c|}{ No PMV } \\
\hline & Sydney & W'gong & Sydney & W'gong & Sydney & W'gong & Sydney & W'gong & Sydney & W'gong & Sydney & W'gong \\
\hline Overseas-born & 12.0 & 11.3 & 37.7 & 38.4 & 50.3 & 50.3 & 61.6 & 83.6 & 3.3 & 2.0 & 35.1 & 14.4 \\
\hline Australian-born & 5.6 & 4.9 & 28.8 & 28.3 & 65.5 & 66.7 & 71.9 & 87.9 & 3.4 & 1.9 & 24.8 & 10.2 \\
\hline Duration of residence in Australia & & & & & & & & & & & & \\
\hline 5 years or less (arrived 2007-2011) & 22.0 & 18.0 & 46.6 & 41.1 & 31.4 & 40.8 & 39.4 & 64.2 & 2.8 & 2.8 & 57.8 & 33.0 \\
\hline 6 to 10 years (arrived 2002-2006) & 10.6 & 7.0 & 42.9 & 33.5 & 46.5 & 59.5 & 54.8 & 77.6 & 3.5 & 3.4 & 41.7 & 19.0 \\
\hline 11 to 20 years (arrived 1992-2001) & 7.7 & 8.4 & 34.1 & 28.9 & 58.2 & 62.7 & 64.2 & 81.5 & 3.9 & 3.3 & 31.9 & 15.2 \\
\hline 20 years+ (arrived 1991 or earlier) & 9.4 & 10.6 & 34.3 & 39.9 & 56.3 & 49.5 & 72.5 & 87.9 & 3.1 & 1.6 & 24.4 & 10.6 \\
\hline Self-reported ancestry ${ }^{\mathrm{C}}$ & & & & & & & & & & & & \\
\hline Anglo-Australian & 6.4 & 5.3 & 27.9 & 28.2 & 65.7 & 66.5 & 73.8 & 88.4 & 3.0 & 1.6 & 23.3 & 9.9 \\
\hline NW European & 11.1 & 7.8 & 37.8 & 41.3 & 51.1 & 51.0 & 62.6 & 86.6 & 2.8 & 2.0 & 34.6 & 11.4 \\
\hline SE European & 7.9 & 8.2 & 28.9 & 27.7 & 63.2 & 64.1 & 75.0 & 90.0 & 2.5 & 1.5 & 22.5 & 8.5 \\
\hline Nth African \& ME & 6.5 & 10.7 & 28.0 & 39.5 & 65.5 & 49.8 & 77.6 & 79.1 & 2.3 & 2.0 & 20.2 & 18.9 \\
\hline NE Asian & 13.2 & 17.3 & 39.9 & 38.6 & 46.9 & 44.1 & 56.3 & 71.4 & 3.3 & 1.4 & 40.4 & 27.2 \\
\hline SE Asian & 9.2 & 14.7 & 32.5 & 42.2 & 58.3 & 43.1 & 61.6 & 76.1 & 4.8 & 2.4 & 33.6 & 21.5 \\
\hline Sth \& Central Asian & 9.0 & 0.0 & 40.6 & 55.1 & 50.4 & 44.9 & 53.7 & 73.2 & 4.2 & 3.0 & 42.1 & 23.8 \\
\hline
\end{tabular}

Source: Australian Census of Population and Housing 2011; Table Builder and Census Sample Files.

${ }^{\mathrm{a}}$ Percentage of persons living in a dwelling with 0,1 or $2+$ personal motor vehicles (excluding motorbikes and motor scooters).

' The Census asked 'How did the person get to work on Tuesday, 9 August 2011?' (PMV for method of transport included motorbikes and motor scooters).

${ }^{\mathrm{c}}$ Based on first ancestry response only (excludes persons who stated more than one ancestry). 
Table 2: PMV ownership and use, and transport-related attitudes (survey data)

\begin{tabular}{|c|c|c|c|c|c|c|c|c|}
\hline & \multicolumn{2}{|c|}{ Country of birth } & \multicolumn{2}{|c|}{ Duration of residence $^{\mathrm{a}}$} & \multicolumn{4}{|c|}{ Ethnicity/ancestry ${ }^{\mathrm{b}}$} \\
\hline & Australia & Other & $\leq 10$ years & $\geq 11$ years & Anglo-Aust. & NE Asian & SE Asian & Sth \& Cent.Asian \\
\hline Money spent on petrol per week: $\$ 50$ or more per capita & 25.8 & $15.8 *$ & $6.5 * *$ & 18.0 & 24.2 & $7.8 * *$ & 12.3 & $8.5^{\mathrm{C}}$ \\
\hline PMVs per household $=0$ & 8.3 & 10.9 & 14.9 & 9.4 & 8.3 & $22.9 * *$ & 6.9 & 8.2 \\
\hline PMVs per adult household member: $<1$ & 38.9 & 64.1** & $80.3^{* *}$ & $59.4 * *$ & 38.9 & $75.0 * *$ & $60.3^{*}$ & $75.0 * *$ \\
\hline Large vehicles owned by household: Yes & 38.9 & $24.4^{* *}$ & $17.9 * *$ & $26.4 * *$ & 37.2 & $14.4 * *$ & 27.6 & 22.4 \\
\hline Work/study trip: PMV only & 67.2 & $51.8 * *$ & $36.5^{* *}$ & 55.5 & 65.5 & 47.9* & 44.2 & 51.1 \\
\hline Work/study trip: Combination & 10.6 & $24.1 * *$ & $30.2 * *$ & $22.7^{*} *^{\mathrm{d}}$ & 12.0 & 15.5 & $34.6^{* *} \mathrm{c,d}$ & 15.6 \\
\hline Work/study trip: Active/public transport only & 22.2 & 24.1 & 33.3 & 21.8 & 22.5 & $36.6 *$ & 21.2 & 33.3 \\
\hline Grocery shopping trip: PMV only & 78.9 & 69.9 & $56.1^{* *}$ & 73.9 & 79.3 & $53.1 * *$ & 75.9 & $65.3^{c}$ \\
\hline Grocery shopping trip: Combination & 8.3 & 13.0 & 16.7 & 12.7 & 10.1 & 13.5 & 15.5 & 14.3 \\
\hline Grocery shopping trip: Active/public transport only & 12.7 & 17.1 & $27.3^{* *}$ & 13.5 & 10.6 & $33.3^{* *}$ & 8.6 & $20.4^{c}$ \\
\hline Recreational trips: PMV only & 58.5 & 57.7 & 52.3 & 59.1 & 59.7 & 50.0 & 63.6 & 57.4 \\
\hline Recreational trips: Combination & 25.9 & 22.9 & 26.2 & 22.6 & 26.7 & 18.2 & 23.6 & 21.3 \\
\hline Recreational trips: Active/public transport only & 15.6 & 19.4 & 21.5 & 18.3 & 13.6 & $31.8^{* *}$ & 12.7 & 21.3 \\
\hline Social trips: PMV only & 64.8 & 63.4 & $50.8^{\mathrm{C}}$ & 66.4 & 64.6 & 49.5 & 70.4 & 70.2 \\
\hline Social trips: Combination & 22.5 & 23.6 & 30.8 & 22.6 & 22.5 & 18.7 & 25.9 & 21.3 \\
\hline Social trips: Active/public transport only & 12.8 & 12.9 & 18.5 & 11.1 & 12.9 & $31.9 * *$ & 3.7 & 8.5 \\
\hline I combine car trips to save petrol: Always & 18.6 & $32.7^{*} *^{\mathrm{d}}$ & 32.8 & $33.2^{*} *{ }^{\mathrm{d}}$ & 16.9 & 41.1** & 30.4 & 28.3 \\
\hline I walk or ride for short trips : Always & 13.6 & $26.5 *$ & $36.9 * *$ & 22.6 & 12.6 & $30.0 *$ & 29.1 & $32.7 *$ \\
\hline I use public transport whenever possible: Always & 9.8 & $25.8^{* *}$ & $35.8^{* *}$ & $22.7 * *$ & 9.7 & $27.0 * *$ & $32.1^{* *}$ & $32.0 * *$ \\
\hline I carpool: Always & 6.8 & 7.0 & 6.3 & 7.5 & 5.3 & 11.8 & 9.4 & 6.4 \\
\hline We are dependent on motor vehicles: Disagree ${ }^{e}$ & 9.7 & $20.6^{* *}$ & $33.3 * *$ & $17.1^{* *}$ & 8.4 & $25.3^{* *}$ & $22.8^{*^{\mathrm{c}, \mathrm{d}}}$ & $28.0^{*} * *^{\mathrm{d}}$ \\
\hline We are concerned about the cost of fuel: Agree $^{\mathrm{f}}$ & 82.0 & 79.6 & 68.2 & 81.9 & 79.9 & 75.9 & 84.2 & 81.6 \\
\hline We are concerned about the env't impacts of driving: Agree $^{\mathrm{f}}$ & 54.6 & 59.9 & 44.8 & 63.0 & 57.3 & 53.4 & 66.7 & 68.0 \\
\hline We would only travel by public trans. if no other choice: Agree ${ }^{\mathrm{f}}$ & 47.4 & 50.8 & 37.3 & 54.4 & 45.8 & 49.5 & 53.4 & 48.0 \\
\hline
\end{tabular}

Source: Diverse Cultures, Diverse Households survey, $\mathrm{n}=578$

${ }^{*} \mathrm{p}<0.05,{ }^{* *} \mathrm{p}<0.01$ (Pearson's chi-squared test)

Grey shading indicates a result became/remained significant after controlling for demographic factors (gender, generation, income, employment status, presence of dependent children). Bold text indicates a result became/remained significant after controlling for place of residence (Sydney or Wollongong)

${ }^{\mathrm{a} S}$ Significant differences in relation to duration of residence are measured against the Australian-born group.

${ }^{\mathrm{b}}$ Significant differences in relation to ethnicity are measured against the Anglo-Australian group.

${ }^{\mathrm{c}}$ Ordinal regression output could not be interpreted for location of residence (Sydney/Wollongong) as the criteria for analysis were not met.

${ }^{\mathrm{d}}$ Ordinal regression output could not be interpreted for demographic factors as the criteria for analysis were not met.

${ }^{\mathrm{e}}$ Includes strongly disagree + disagree.

${ }^{\mathrm{f}}$ Includes strongly agree + agree. 